E International

\title{
Evolution of Technology for Commercial Vehicle Safety
}

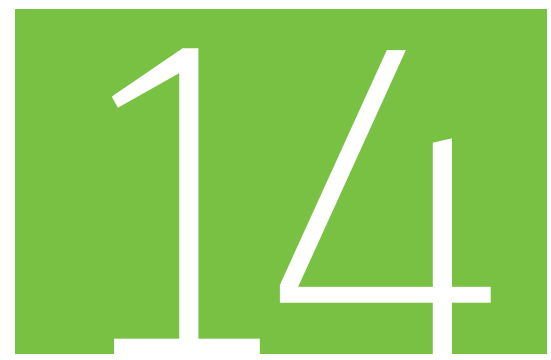

Discussion Paper 2017•14

Peter Sweatman 


\title{
F International Transport Forum
}

\section{Evolution of Technology for Commercial Vehicle Safety}

Discussion Paper 2017-14

\author{
Prepared for the Roundtable on
}

Commercial Vehicle On-Board Safety Systems

January $5-6,2017$

Washington DC

\author{
Peter Sweatman \\ CAVita LLC \\ www.cavitatrans.com
}

August 2017 


\section{The International Transport Forum}

The International Transport Forum is an intergovernmental organisation with 59 member countries. It acts as a think tank for transport policy and organises the Annual Summit of transport ministers. ITF is the only global body that covers all transport modes. The ITF is politically autonomous and administratively integrated with the OECD.

The ITF works for transport policies that improve peoples' lives. Our mission is to foster a deeper understanding of the role of transport in economic growth, environmental sustainability and social inclusion and to raise the public profile of transport policy.

The ITF organises global dialogue for better transport. We act as a platform for discussion and prenegotiation of policy issues across all transport modes. We analyse trends, share knowledge and promote exchange among transport decision-makers and civil society. The ITF's Annual Summit is the world's largest gathering of transport ministers and the leading global platform for dialogue on transport policy.

The Members of the Forum are: Albania, Armenia, Argentina, Australia, Austria, Azerbaijan, Belarus, Belgium, Bosnia and Herzegovina, Bulgaria, Canada, Chile, China (People's Republic of), Croatia, Czech Republic, Denmark, Estonia, Finland, France, Former Yugoslav Republic of Macedonia, Georgia, Germany, Greece, Hungary, Iceland, India, Ireland, Israel, Italy, Japan, Kazakhstan, Korea, Latvia, Liechtenstein, Lithuania, Luxembourg, Malta, Mexico, Republic of Moldova, Montenegro, Morocco, the Netherlands, New Zealand, Norway, Poland, Portugal, Romania, Russian Federation, Serbia, Slovak Republic, Slovenia, Spain, Sweden, Switzerland, Turkey, Ukraine, the United Arab Emirates, the United Kingdom and the United States.

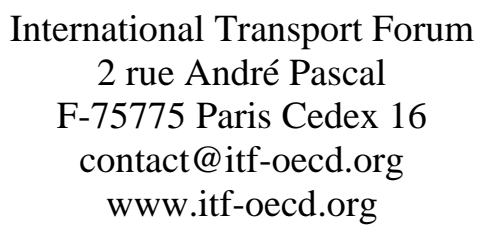

\section{ITF Discussion Papers}

ITF Discussion Papers make economic research, commissioned or carried out in-house at ITF, available to researchers and practitioners. They describe preliminary results or research in progress by the author(s) and are published to stimulate discussion on a broad range of issues on which the ITF works. Any findings, interpretations and conclusions expressed herein are those of the authors and do not necessarily reflect the views of the International Transport Forum or the OECD. Neither the OECD, ITF nor the authors guarantee the accuracy of any data or other information contained in this publication and accept no responsibility whatsoever for any consequence of their use. This document and any map included herein are without prejudice to the status of or sovereignty over any territory, to the delimitation of international frontiers and boundaries and to the name of any territory, city or area. Comments on Discussion Papers are welcome. 
Peter Sweatman - Evolution of Technology for Commercial Vehicle Safety

\section{Acknowledgements}

The author is grateful for the heavy truck safety research programs conducted by his former colleagues at the University of Michigan Transportation Research Institute (UMTRI). 


\begin{abstract}
Heavy commercial vehicle technology for safety has developed in capability and application and is having a positive impact on truck safety. And the potential for further safety improvements is exciting. We wish to place the evolution of such technology in perspective with related developments for light vehicles and the rapid convergence of a number of transformational technologies in transportation. These technologies affect vehicles, drivers and infrastructure, and are now having a much broader impact on adjacent industries and new "disruptive" entrants in the transportation sector.

Transformational technologies under consideration include connected vehicles (CVs) and automated vehicles (AVs), as well as shared mobility (SM), smart cities and communities (SCCs), alternative-fuel vehicles (AFVs) and big data analytics. As heavy vehicle technologies move beyond Advanced Collision Avoidance Systems (ACAS) towards connected and automated vehicles (CAV), it is important to consider contextual issues that apply to freight vehicles very differently from light vehicles. It is hoped that the roundtable will shed light on the way forward for the heavy vehicle sector in its own technological right.

$\mathrm{CV}$ is more significant for heavy commercial vehicles than for light vehicles because the organized nature of heavy vehicle operations benefits more from connectivity. Fleets have an important role to play in deploying the technology, engaging with smart cities and communities, establishing connected corridors and precincts, and developing new accommodations for heavy vehicles, including signal priority and truck parking.

AV for heavy commercial vehicles offers immediate benefits in terms of automated features that assist drivers. Automated features that support or relieve the heavy vehicle driver in well-defined circumstances will play an important role in advancement of the freight industry. Some significant uncertainties need to be navigated before highly-automated vehicles (HAVs) play an important role for heavy vehicles.
\end{abstract}




\section{Table of contents}

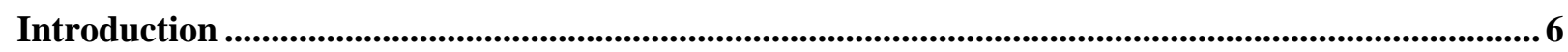

Safety technology trend for heavy trucks has been influenced by light vehicles .................................. 6

Specific technologies for heavy trucks have become more evident ...................................................7

Transformational technology is accelerating the rate of change......................................................8

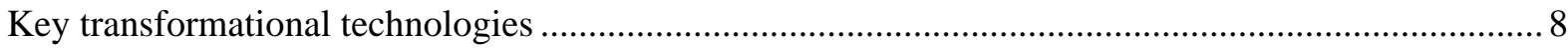

Heavy truck technological transformation in its own right..............................................................11

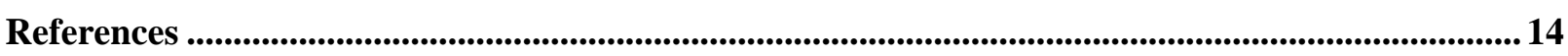

Table

Table 1. Deployment considerations for light vehicles and heavy vehicles by technology 


\section{Introduction}

Heavy commercial vehicle technology for safety has developed in capability and application and is having a positive impact on truck safety. And the potential for further safety improvements is exciting. We wish to place the evolution of such technology in perspective with related developments for light vehicles and the rapid convergence of a number of transformational technologies in transportation. These technologies affect vehicles, drivers and infrastructure, and are now having a much broader impact on adjacent industries and new "disruptive" entrants in the transportation sector.

Transformational technologies under consideration include connected vehicles (CVs) and automated vehicles (AVs), as well as shared mobility (SM), smart cities and communities (SCCs), alternative-fuel vehicles (AFVs) and big data analytics. As heavy vehicle technologies move beyond Advanced Collision Avoidance Systems (ACAS) towards connected and automated vehicles (CAV), it is important to consider contextual issues that apply to freight vehicles very differently from light vehicles. It is hoped that the roundtable will shed light on the way forward for the heavy vehicle sector in its own technological right.

\section{Safety technology trend for heavy trucks has been influenced by light vehicles}

On-board safety systems for heavy commercial vehicles (HCVs) have been developed and implemented over a considerable period of time, ranging from anti-lock braking systems and speed control, through stability control, forward collision warning, lane departure warning, adaptive cruise control and driver drowsiness monitoring, to crash-imminent braking. Research has shown these systems to be effective in reducing crashes - in some cases, highly effective - and implementation has taken place through the voluntary action of manufacturers and fleets, and in some cases through government-mandated requirements for new vehicles.

All of the safety systems mentioned above started as light vehicle applications and were adapted to heavy trucks, and in some cases took on a different flavor for heavy trucks. The National Highway Traffic Safety Administration (NHTSA) has conducted a multi-decadal program of field operational tests (FOTs) to quantify the likely safety benefits of these and other applications. A good example is the Integrated Vehicle Based Safety Systems (IVBSS) FOT conducted by the University of Michigan Transportation Research Institute (UMTRI). This FOT (Bezzina \& Sayer 2015) included fleets of cars and heavy trucks, with essentially the same technologies fitted to both. As a result of such studies, certain driver assist technologies were included in NHTSA's safety ratings applicable to light vehicles. In the heavy truck sector, no such institutional arrangements occurred, and fleets had the option to fit the technologies as made available by the heavy truck supplier industry.

Through such programs, NHTSA has been able to work successfully with Original Equipment Manufacturers (OEMs) to make Advanced Collision Avoidance Systems (ACAS) a well-accepted pillar of automotive safety. A large number of options are made available at the original equipment level and are well-accepted by consumers. However, the application of the technologies to heavy trucks has been more at the discretion of OEMs and fleets. 
Therefore, the fitment of ACAS to heavy trucks has lagged its fitment to light vehicles, and its use has been less widespread. There are many good reasons for this, including less-than-universal information on technology effectiveness, and additional complexities in fitting some systems to long or articulated vehicles. A fleet survey carried out by ITS America (2014) found relatively low penetration rates for technologies such as electronic stability control (ESC), forward collision warning, lane departure warning and blind spot detection warning.

\section{Specific technologies for heavy trucks have become more evident}

In certain cases, NHTSA has pursued mandatory fitment of highly-promising safety applications to heavy trucks. A recent example is ESC, where research found the benefits to be greater for heavy trucks than for cars. Automated emergency braking (AEB) also has potential for deployment via federal motor vehicle regulation for heavy trucks. Meanwhile, heavy truck fleet acquisitions are increasingly opting for forward collision warning, lane departure warning and adaptive cruise control.

At the same time, commercial vehicle safety has been enhanced by a range of technologies that are designed to improve the safety of fleets and drivers. Such approaches include on-board monitoring, driver evaluation and training, vehicle condition monitoring, driver aids such as field-of-view cameras, journey management planning and route design. Related services are available to create useful information from the increasing amount of data obtained from such systems. The larger fleets are active in developing in-house programs for continuous improvement, based on judicious use of these technologies and data flows. Certain company philosophies have developed to imprint best practices in company operations, including "branded" safety programs and in some cases giving drivers more control over their schedules.

As federal safety technology efforts have moved beyond systems based in individual vehicles, more specific consideration has been given technologies that benefit the drivers of heavy trucks. The connected vehicle (CV) program, including the elements of vehicle-to-vehicle (V2V) and vehicle-to-infrastructure (V2I), has given greater consideration to heavy truck applications. The CV program's truck driver clinics (Stevens 2016) included the following CV applications that were well-rated by truck drivers:

- $\quad$ intersection movement assist (IMA)

- forward collision warning (FCW)

- emergency electronic brake light scenario (EEBL)

- blind spot warning (BPW)/lane change warning (LCW).

Combining CV with elements of automation, the platooning of trucks has become a leading technology application for the freight industry. Typically, pairs of trucks use V2V communication to control the braking and acceleration of the following vehicle, resulting in significant fuel savings during open-road operation.

The Federal Motor Carrier Safety Administration (FMCSA) (Routhier 2016) is considering various levels of automation in heavy trucks, including constrained environments such as port queues, distribution warehouses and mine haulage. Current Federal Highway Administration (FHWA) projects include partial automation for truck platooning and cooperative adaptive cruise control. 


\section{Transformational technology is accelerating the rate of change}

We are now entering an era of transformation of the mobility of people and freight, driven by connected and automated vehicle (CAV) technologies, public-private collaboration, the sharing economy, "smart cities" platforms alternative-fuel vehicles, and big data analytics. The underlying technologies are cross-cutting, while the deployment of applications and services may vary between the vehicle classes of light vehicle, transit vehicle and heavy truck. The status of deployment of transformational technologies in transportation has been reviewed by Mohaddes and Sweatman (2016).

\section{Key transformational technologies}

\section{CV technology}

The CV wireless platform will support a rich variety of applications, some of which are mentioned above. In the U.S., CVs have been developed primarily for the purpose of deploying safety applications. The CV platform uses Dedicated Short Range Communication (DSRC), a form of Wi-Fi that currently uses part of a 75-MHz slice of licensed spectrum at $5.9 \mathrm{GHz}$. The signal reliability and short latency of this wireless regime are suitable for highly specific safety applications like forward collision warning, electronic brake light assist, or left turn assist. It is possible that future versions of cellular technology, such as $5 \mathrm{G}$, will have adequate technical performance-similar to DSRC - and it would be beneficial if they were considered. The DSRC platform is used to send basic safety messages (BSMs) that contain vehicle position, speed, and heading, as a minimum. BSMs are sent 10 times per second and are received by equipped vehicles and infrastructure equipment in the immediate vicinity.

In December 2016, the U.S. DOT issued a Notice of Proposed Rule Making for V2V (NHTSA 2016a) that speaks to the presence and capability of the DSRC platform, but not to specific applications, the nature of which will be left to automakers. While the rule applies to new vehicles, retrofit and aftermarket CV devices are readily available. Beyond the U.S. national priority for transforming safety, V2V and V2I and infrastructure offer improvements in traffic flow, intersection efficiency, energy wasted in stop-start operations, and vehicle emissions. CVs also have advantages for electrified vehicles.

$\mathrm{CV}$ deployment is a substantial institutional and technical undertaking, on a national scale. The deployment of DSRC roadside equipment in the infrastructure - especially at intersections and on curves - is a necessary development, along with a sufficient density of equipped vehicles in a given traffic stream. This equipment is typically housed in traffic control cabinets, with transmission equipment high-mounted on signal arms, poles, and gantries. The FHWA is expected to soon release guidance for the deployment of V2I, as a companion to the V2V rule. While equipment vendors and the traffic control industry have the necessary technology, the business case for paying for the installation, operation, and maintenance of the roadside equipment is not clear.

Several model deployments have been developed around the country—such as Ann Arbor. Additional deployments are being pursued in New York City, Tampa, and Wyoming. The successful deployment of CVs on a nationwide scale will require a highly strategic and coordinated public-private effort, along with strong decision making by a range of companies from the automotive, traffic control, infrastructure, and technology industries. Deployment of CVs will be a more demanding institutional than technological endeavor. While most model deployments include heavy trucks, the V2V rule does not apply to heavy trucks and NHTSA has not yet announced its intentions for extending the scope of the rule. It should be noted that the Wyoming deployment is focused on a major freight route known for winter weather issues. The applications to be deployed include Road Weather Advisories and Warnings for Motorists and Freight Carriers, Weather-Responsive Variable Speed Limit System, Freight-Specific Dynamic Travel Planning, Spot Weather Impact Warning, Situational Awareness, and others as determined by the user needs of truck drivers, and fleet managers in the corridor. Communication to heavy trucks will either directly utilize V2I, or go via fleet management centers (USDOT JPO 2016). 


\section{AV technology}

AV technology seeks to provide various levels of replacement of human control, with consequences that go well beyond avoidance of specific types of crashes. Many believe that highly-automated vehicles, in combination with shared mobility, could change transportation's role in the economy and society. AVs utilize a range of sensing technologies and maps to create situation awareness; software and actuators to provide control functions (steering, accelerating, and decelerating); and driver interfaces. High levels of automation open the door to radical changes in the architecture and design of vehicles. Dramatic changes in powertrains, size, weight, seating arrangements, amenities, and cargo capacity may be realized. Currently, there is a wide range of levels of automation, as companies from the technology sector and automotive industry vie to create the automated product. Concepts range from "everything somewhere" (totally automated but suited only to certain environments) to "something everywhere" where worthwhile but limited automation may be used quite widely (for example while traveling on major highways) (Shladover and Bishop, 2015).

Initially, governments played a limited role for automated vehicles. A number of U.S. states have adopted legislation applying to the testing and operation of automated vehicles. In these cases, there may be requirements for licensing, incident reporting, and human occupants, and limitations on driverless operation. At the moment, many states have no such legislation, but state-level legislative efforts are increasing.

The AV industry is rapidly-changing and represents a "hot topic" from the perspective of the general public, as well as the business community. While most of the publicity pertains to AV in personal vehicles, freight vehicles are involved through the well-known activities of companies such as Peleton and the Uber subsidiary Otto.

Federal safety rules are expected to eventually apply to automated vehicle performance. Standards development is underway on several fronts, and it is likely that standards will operate on at least two levels: (1) the more traditional performance specification where physical testing is implied, and (2) safe systems design standards. The development of norms for human intervention with the machine, or for the coexistence of automated and traditional vehicles on the same roadways, is considered by many to be a significant challenge.

In September 2016, NHTSA released its guidance (NHTSA 2016b) for the pre-deployment testing of automated vehicles, and concentrated on highly-automated vehicles (HAVs), as follows: "This Guidance is intended for vehicles that are tested and deployed for use on public roadways. This includes light-, medium-, and heavy-duty vehicles. This Guidance targets vehicles that incorporate HAV systems, such as those for which there is no human driver at all, or for which the human driver can give control to the HAV system and is not be expected to perform any driving-related tasks for a period of time." Entities covered by the guidance include "automated fleet operators". HAVs are generally described as meeting SAE Levels 3 - 5 of vehicle automation:

- $\quad$ At SAE Level 3, an automated system can both actually conduct some parts of the driving task and monitor the driving environment in some instances, but the human driver must be ready to take back control when the automated system requests.

- $\quad$ At SAE Level 4, an automated system can conduct the driving task and monitor the driving environment, and the human need not take back control, but the automated system can operate only in certain environments and under certain conditions.

- $\quad$ At SAE Level 5, the automated system can perform all driving tasks, under all conditions that a human driver could perform them.

The NHTSA guidelines entail a much broader view of motor vehicle regulation than we have seen in the past. NHTSA's expectations of industry, including manufacturers and suppliers, cover practices for testing and deploying HAVs and for sharing data. Manufacturers and other entities are expected to voluntarily provide a Safety Assessment to NHTSA. In addition to expected safety and testing matters, this assessment includes consumer education and training, and ethical considerations.

For each automation function, driving environments and system capabilities are described in terms of Operational Design Domains (ODDs) and Object and Event Detection and Response (OEDR). "The ODD, which 
may vary for each HAV system, will define the conditions in which that function is intended to operate with respect to roadway types, geographical location, speed range, lighting conditions for operation (day and/or night), weather conditions, and other operational domain constraints. A well-defined ODD is necessary to determine what OEDR capabilities are required for the HAV to safely operate within the intended domain. OEDR requirements are derived from an evaluation of normal driving scenarios, expected hazards (e.g., other vehicles, pedestrians), and unspecified events (e.g., emergency vehicles, temporary construction zones) that could occur within the operational domain."

"Within its ODD, an HAV's OEDR functions are expected to be able to detect and respond to other vehicles (in and out of its travel path), pedestrians, cyclists, animals, and objects that could affect safe operation of the HAV. Within its ODD, an HAV's OEDR should be able to deal with a variety of conditions, including emergency vehicles, temporary work zones, and other unusual conditions (e.g., police manually directing traffic, construction worker controlling traffic, emergency response workers) that may impact safe operations of an HAV."

The NHTSA Automated Vehicles Policy is subject to public comment and outreach and is therefore not final. NHTSA is motivated to enable the full safety potential of HAVs, and to ensure that "these technologies are safely introduced (ie. do not introduce significant new safety risks)". Clearly these objectives apply to have trucks as much as to light vehicles, but the range of responsibilities, considerations and requirements will impact heavy vehicles very differently from light vehicles. Finally, affected entities in the heavy vehicle sector will be less prepared and less equipped to address such responsibilities in a timely manner.

\section{Shared mobility}

Shared mobility (SM) represents one of the most immediate ways of deploying HAVs on a large scale for personal transportation. Transport Network Companies (TNCs) are already carrying our trials of driverless taxis in several cities. Examples include Pittsburg and San Francisco (soon to be relocated). Partnerships between automakers and TNCs (eg. GM and Lyft) will accelerate the trend to automated, shared vehicles. SM is expected to be effective in bringing about HAV deployment because TNCs provide a real-time customer interface and because they have established operations and agency relationships in many cities.

The shared mobility concept may be applied to freight delivery, whereby unused load capacity may be accessed on freight vehicles. At the present time, it has been recognized that courier network services (CNSs) represent a for-hire service model in the broader shared mobility economy (Shaheen et al 2016).

Relative to personal transportation, where there is a powerful synergy between AV and SM, the connection is much less evident in the freight sector.

\section{Smart cities and communities}

Smart cities thinking came to fruition during 2016, especially with the U.S. DOT Smart City Challenge, which was awarded to Columbus OH. Subsequently, the U.S. DOT announced additional awards through the Advanced Transportation and Congestion Management Technologies Deployment (ATCMTD) program of FHWA. These programs have a strong element of CAV deployment, and include freight vehicle projects. For example, the suite of projects being undertaken in Columbus includes Smart Logistics, and provides for DSRC in a freight corridor, as well as city-wide information on truck parking, truck routing and truck delivery. As part of the Columbus project, lower-speed truck platooning for accessing freight precincts is being actively considered.

\section{Alternative-fuel vehicles}

It is likely that many HAVs for personal transportation will also be electrified. Driverless vehicles ("Level 5" vehicles) open the door to tailored design for specific environments, including significant reduction in vehicle weight. Electrified vehicle (EV) technology is part of the advanced design concept for such vehicles and major OEMs and automotive suppliers are developing personal vehicles that are both automated and electrified. The deployment of EVs is a major component of the Columbus smart city program 


\section{Big data analytics}

Smart cities programs include data collection, curation and analytics as highly-visible program components. For example, Columbus is working with Amazon Web Services for city-wide data organization, analytics and performance measurement across all program components. The deployment of HAVs entails extensive data collection by private companies and public agencies, and it is anticipated that new ways of sharing data will be needed to maintain progress. While we are at an early stage, such considerations will also need to apply to freight vehicles.

\section{Heavy truck technological transformation in its own right}

We have seen that heavy trucks have benefited from light vehicle on-board safety technologies. However, as the vehicle technologies have become more transformational - creating a larger ecosystem - there has been a greater need for heavy-truck-specific deployment actions. The advent of CAV has necessitated much greater consideration of the operating context, and there is a big difference between the automated operating contexts of light personal vehicles and heavy commercial vehicles. For example, widespread use of highly-automated vehicles has dramatic implications for freight vehicles, their drivers and employment in the industry. Those implications will be both positive and negative, and will incur issues that would not arise for technological change in personal vehicles.

Table 1 provides a summary of deployment considerations for increasingly transformational technologies, as they apply to light vehicles and as they apply to heavy vehicles. It is apparent that the newer, more transformational technologies require specific actions for heavy vehicle deployment. The industries engaged in the future of freight mobility cannot afford to rely on solutions provided by the light vehicles sector.

$\mathrm{CV}$ is more significant for heavy commercial vehicles than for light vehicles because the organized nature of heavy vehicle operations benefits more from connectivity. Fleets have an important role to play in deploying the technology, engaging with smart cities and communities, establishing connected corridors and precincts, and developing new accommodations for heavy vehicles, including signal priority and truck parking.

AV for heavy commercial vehicles offers immediate benefits in terms of automated features that assist drivers. As we have seen, AV covers a diverse field - from automated features to HAVs. This dichotomy is more marked for heavy vehicles than for light vehicles. Automated features are highly relevant to heavy vehicles in the short term, while HAV technology in trucks faces very significant uncertainties, such as: avoiding any earlyadopter increase in safety risks, developing safety metrics for HAVs, interaction of HAVs with conventional vehicles, ethical design principles and cybersecurity. Automated features that support or relieve the heavy vehicle driver in well-defined circumstances will play an important role in advancement of the freight industry.

The current enthusiasm for truck platooning provides an instructive example of the landscape before us. It is a well-defined use case combining $\mathrm{CV}$ and $\mathrm{AV}$, and leveraging existing vehicle technologies for acceleration and deceleration of the vehicle. It provides an economic incentive for fleets in the form of reduced fuel consumption. How may further use cases be developed and deployed? The impact of traffic congestion on the movement of heavy vehicles is of concern to road agencies and commercial fleets alike. CV-equipped trucks will be able to take advantage of applications such as SPAT and intersection movement assist. Such applications are intended to improve mobility and safety. 
Table 1. Deployment considerations for light vehicles and heavy vehicles by technology

\begin{tabular}{|c|c|c|}
\hline \multirow[t]{2}{*}{ Technology } & \multicolumn{2}{|c|}{ Deployment considerations } \\
\hline & Light personal vehicle & Heavy commercial vehicle \\
\hline ACAS & $\begin{array}{l}\text { NHTSA rulemaking \& safety } \\
\text { advisories; consumer awareness and } \\
\text { demand. }\end{array}$ & $\begin{array}{l}\text { Similar to light vehicle technology; NHTSA } \\
\text { rulemaking; fleet safety programs. }\end{array}$ \\
\hline $\mathrm{CV}$ & $\begin{array}{l}\text { NHTSA rulemaking; FHWA guidance; } \\
\text { AASHTO policy studies; traffic control } \\
\text { and aftermarket products \& personal } \\
\text { devices; not yet converging with AV. }\end{array}$ & $\begin{array}{l}\text { Similar to light vehicle technology; important } \\
\text { role for fleets; potential for signal priority, } \\
\text { corridors and precincts; platooning leads the } \\
\text { way; converging with AV. }\end{array}$ \\
\hline AV & $\begin{array}{l}\text { NHTSA OEM agreement; NHTSA } \\
\text { automated vehicles policy; includes } \\
\text { Operational Design Domains; the path } \\
\text { to HAV has uncertainty. }\end{array}$ & $\begin{array}{l}\text { NHTSA automated vehicles policy applies; } \\
\text { specific ODDs to be developed; platooning } \\
\text { leads the way; increasing AV features assist } \\
\text { drivers and support safety; the path to HAV } \\
\text { has greater uncertainty. }\end{array}$ \\
\hline $\begin{array}{l}\text { Shared mobility } \\
(\mathrm{SM})\end{array}$ & $\begin{array}{l}\text { Potentially a major enabler of HAV; } \\
\text { little data available; uncertainties } \\
\text { concerning economic impacts. }\end{array}$ & $\begin{array}{l}\text { Currently little impact on heavy freight } \\
\text { vehicles; potential impact for "last mile" } \\
\text { HAVs. }\end{array}$ \\
\hline $\begin{array}{l}\text { Smart cities and } \\
\text { communities } \\
\text { (SCCs) }\end{array}$ & $\begin{array}{l}\text { Major provider of avenues for CAV, } \\
\text { SM, alternative fuel vehicle and data } \\
\text { analytics deployments; venues for } \\
\text { technology bundling: shared, } \\
\text { automated, electrified vehicles. }\end{array}$ & $\begin{array}{l}\text { CAV corridors and precincts represent more } \\
\text { permanent use cases for heavy vehicles; } \\
\text { potential for heavy truck accommodations } \\
\text { once the technology is deployed; equipped } \\
\text { heavy vehicles take the technology across the } \\
\text { country. }\end{array}$ \\
\hline $\begin{array}{l}\text { Alternative fuel } \\
\text { vehicles (AFVs) }\end{array}$ & $\begin{array}{l}\text { CAV and EV are mutually reinforcing } \\
\text { for increasing deployment. HAVs have } \\
\text { a commercial affinity with } \\
\text { electrification. }\end{array}$ & $\begin{array}{l}\text { Limited potential for AFVs in heavy vehicles; } \\
\text { electrified HAVs are of significance for last } \\
\text { mile delivery. }\end{array}$ \\
\hline Big data analytics & $\begin{array}{l}\text { Developments in CAV data curation, } \\
\text { access, sharing and analytics are } \\
\text { needed to support HAV deployment; } \\
\text { new independent roles to be } \\
\text { established. }\end{array}$ & $\begin{array}{l}\text { Shared CAV data is necessary for deployment, } \\
\text { and has a bigger purpose: supporting public } \\
\text { agency investment in the supply chain through } \\
\text { corridors and precincts. }\end{array}$ \\
\hline
\end{tabular}

Collaboration between companies in the freight sector, including fleets, and agencies at the state, regional and local level has the potential to deploy mutually-beneficial use cases making the most of CV-equipped heavy trucks operating widely. Companies in the traffic control and CV communications sectors have much to gain through cooperation with fleet operators. More efficient flow of heavy trucks on highways and signalized corridors is a timely and relevant goal for CV application development.

Truck driver assist technology has further potential for improving safety. Pending higher densities of CV deployment, AV features such as automated emergency braking, blind spot warning, adaptive cooperative cruise control and lane keeping are likely to be deployed by fleets in advanced safety programs. 
The freight industry has good reason to support and deploy CAV technologies. The two heavy vehicle technology streams of $C V$ traffic efficiency and $A V$ safety will increasingly converge and generate data for fleet management and road network management purposes, and will also support data-driven investment in improving the supply chain. 


\section{References}

Bezzina, D. and J. Sayer (2015), "Safety Pilot Model Deployment: Test Conductor Team Report", DOT HS 812 171, NHTSA.

Routhier, B. (2016), “Automated Commercial Motor Vehicles: State of the Industry and Potential Safety Impacts", Federal Motor Carrier Safety Administration, Transportation Research Board 95 ${ }^{\text {th }}$ Annual Meeting, Washington D.C.

Shaheen, S., A. Cohen and A. Zohdy (2016), "Shared Mobility: Current Practices and Guiding Principles", FHWA-HOP-16-022.

Shladover, S. and R. Bishop (2015), "Road Transport Automation as a Public-Private Enterprise", White Paper 1, TRB EU-US Symposium on Automated Vehicles, April 2015, Washington D.C.

Stevens, S. (2016), "Driver Acceptance of Collision Warning Applications Based on Heavy Truck V2V Technology", Volpe National Transportation Systems Center, Cambridge, MA.

U.S. DOT, ITS Joint Program Office (2016), “CV Pilot Deployment Program", http://www.its.dot.gov/pilots/wave1.htm.

U.S. DOT, NHTSA (2016a), "Federal Motor Vehicle Safety Standards; V2V Communications", 49 CFR Part 571.

U.S. DOT, NHTSA (2016b), “Federal Automated Vehicles Policy”, September 2016. 
